\title{
Characterization of long-term and seasonal variations of black carbon (BC) concentrations at Neumayer, Antarctica
}

\author{
R. Weller ${ }^{1}$, A. Minikin ${ }^{2}$, A. Petzold ${ }^{2,}{ }^{*}$, D. Wagenbach ${ }^{3}$, and G. König-Langlo ${ }^{1}$ \\ [1] Alfred Wegener Institute for Polar and Marine Research, Am Handelshafen 12, D-27570 \\ Bremerhaven, Germany \\ [2] Deutsches Zentrum für Luft- und Raumfahrt (DLR), Institut für Physik der Atmosphäre, \\ Oberpfaffenhofen, D-82234 Weßling, Germany \\ [3] Institut für Umweltphysik, University Heidelberg, Im Neuenheimer Feld 229, D-69120 \\ Heidelberg, Germany \\ [*] now at: Forschungszentrum Jülich $\mathrm{GmbH}$, Institut für Energie- und Klimaforschung IEK-8: \\ Troposphäre, D-52425 Jülich, Germany
}

\section{SUPPLEMENTARY MATERIAL}




\section{Scattering coefficients (nephelometer data)}

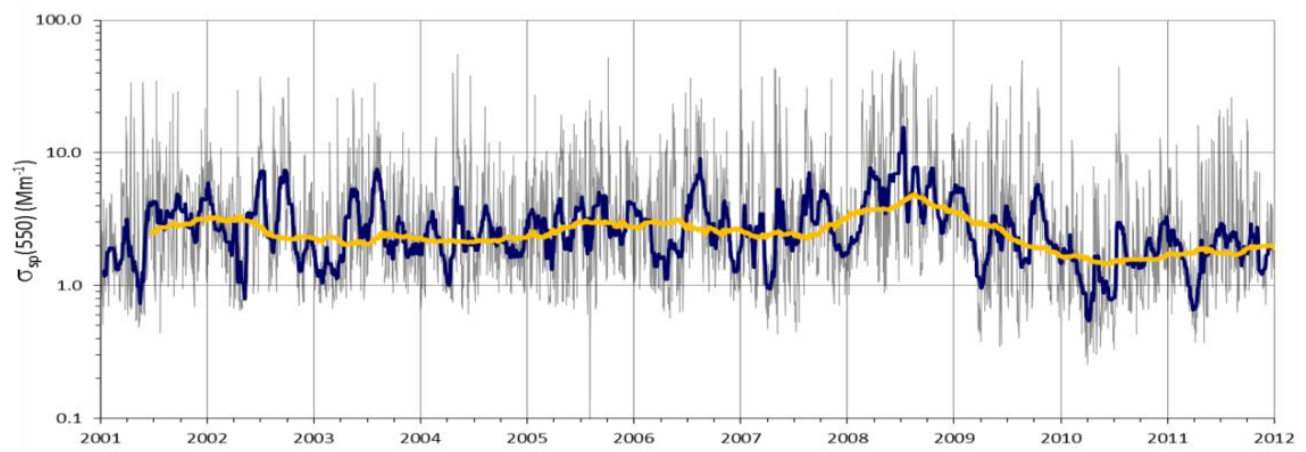

Fig. S.1. Timeseries of scattering coefficients measured at $550 \mathrm{~nm}\left(\sigma_{\mathrm{sp}}(550)\right)$ : Daily means (grey line), 31-days and 365-days running medians (blue line and yellow line, respectively).

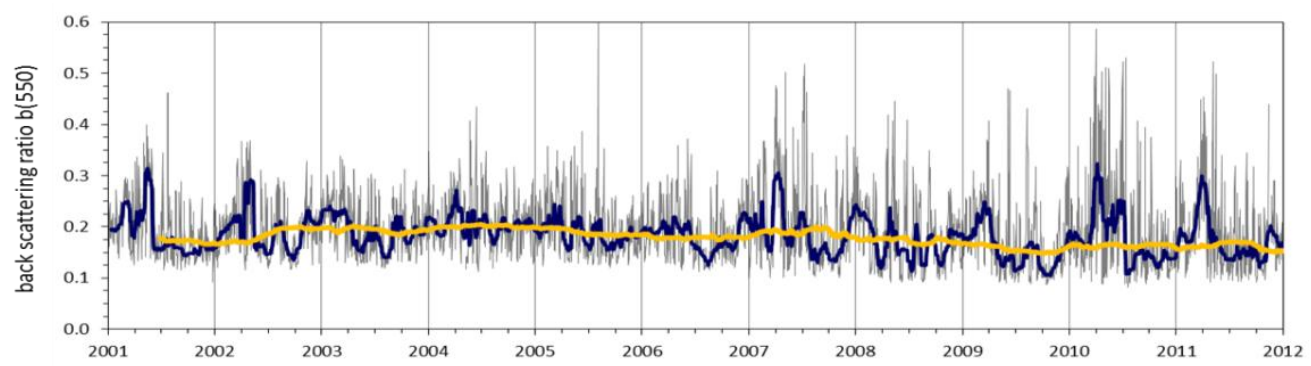

Fig. S.2. Timeseries of the hemispheric back-scattering fraction measured at $550 \mathrm{~nm}$ (b(550)): daily means (grey line), 31-days and 365-days running medians (blue line and yellow line, respectively).

As for $\sigma_{\mathrm{sp}}(550)$ and $\mathrm{b}(550)$, no significant overall trend could be detected. For $\sigma_{\mathrm{sp}}(550)$, however, an annual cycle with a broad winter maximum was identifiable (not shown). The remarkably high $\sigma_{\mathrm{sp}}(550)$ values during 2008 may again be a result of the NM III construction activities. Furthermore we speculate that extremly low sea salt aerosol concentrations throughout 2010 entailed strikingly low $\sigma_{\mathrm{sp}}(550)$ values during this year. As shown by Weller and Lampert (2008), sea salt aerosol is the dominant aerosol species affecting aerosol optical properties at NM, except for January and February when biogenic sulfur aerosol dominates. 


\section{Surface albedo}

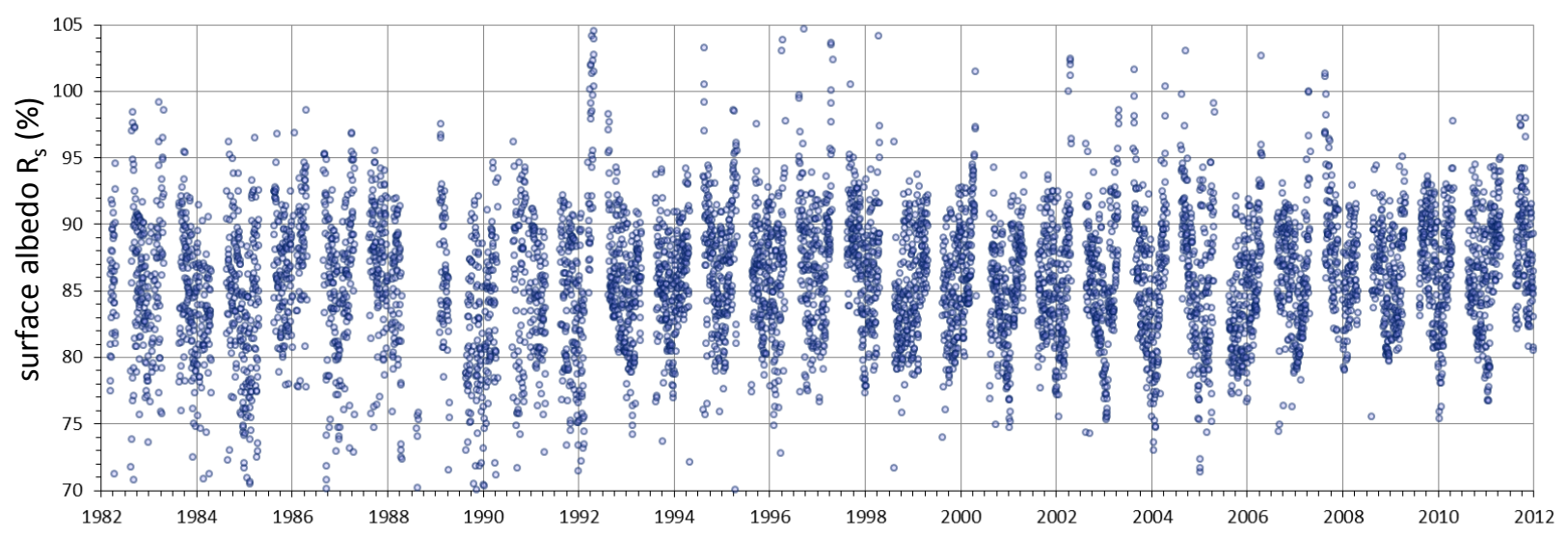

Fig. S.3a. Timeseries of broad band surface albedo $\mathrm{R}_{\mathrm{s}}$, (daily means, wavelength range $305 \mathrm{~nm}$ to $2800 \mathrm{~nm}$ ). Note that $\mathrm{R}_{\mathrm{s}}$ values were not available between end of April and early August of each year, because then solar radiation was below $10 \mathrm{~W} \mathrm{~m}^{-2}$ and $\mathrm{R}_{\mathrm{s}}$ could not be reliably determined.

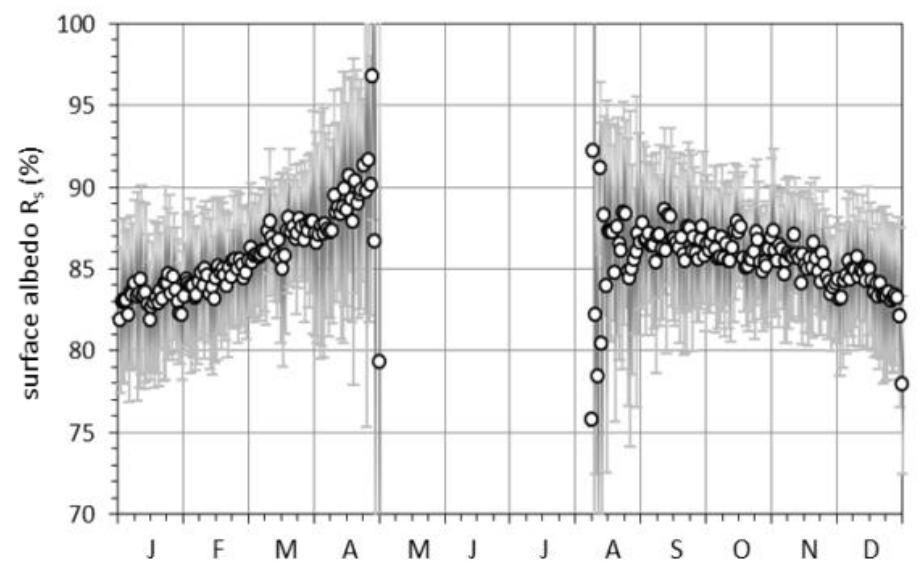

Fig. S.3b. Seasonality of broad band surface albedo $\mathrm{R}_{\mathrm{s}}$, (based daily means; error bars represent the respecting standard deviation).

A problem interfering snow albedo measurements which is hard to overcome is the increasingly inclined snow surface resulting from enhanced snow accumulation west of the radiation field due to prevaling easterly winds. We suggest that the seasonality of $\mathrm{R}_{\mathrm{s}}$ with distinctly higher and more variable values towards winter (Fig. S.3b) was hardly caused by a higher snow albedo (induced by probably smaller snow grains at lower temperature) but rather an artifact provoked by an interplay of high solar zenith angles and surface roughness. Note, the same perturbing effect could also be observed under clear sky conditions in diurnal $\mathrm{R}_{\mathrm{s}}$ maxima at high solar zenith angles, vanishing under overcast sky conditions. 


\section{Frequency distribution of $\mathrm{BC}$ concentrations}
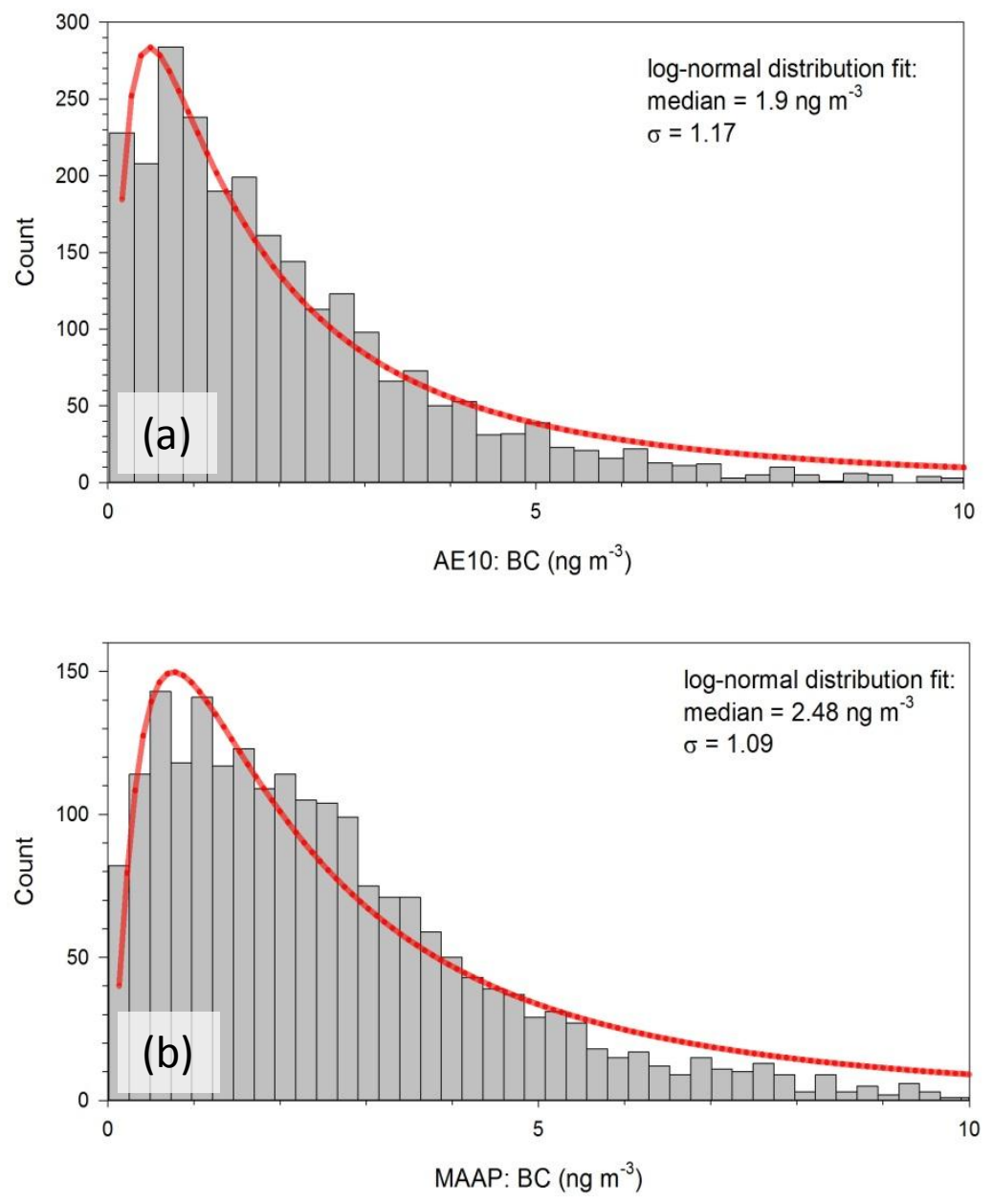

Fig. S.4. Frequency distribution of daily median BC concentrations measured by the AE10 (a) and MAAP (b). The red lines represent lognormal distribution fits $(\mathrm{p}<0.0001)$. 